\title{
EVALUATION OF BIOLOGICAL ACTIVITIES AND STABILITY OF THAI ORGANIC RICEBERRY BROKEN RICE EXTRACTS FOR THE ANTI-AGING COSMETOLOGY
}

\author{
WORRAPAN POOMANEE ${ }^{1 *}$, PIMJAI DOUNGSAARD ${ }^{1}$, NARA NANTHARAT ${ }^{1}$, PIMPORN LEELAPORNPISID ${ }^{1,2}$
}

${ }^{1}$ Department of Pharmaceutical Sciences, Faculty of Pharmacy, Chiang Mai University, Chiang Mai, Thailand. ${ }^{2}$ Innovation Center for Holistic Health, Nutraceuticals, and Cosmeceuticals, Faculty of Pharmacy, Chiang Mai University, Chiang Mai, Thailand. Email: taressential@hotmail.com

Received: 20 June 2020 , Revised and Accepted: 26 July 2020

ABSTRACT

Objective: Thai organic Riceberry rice, deep purple rice, has been known to have the wide variety of nutritional benefits. However, broken rice which accounted for $20-30 \%$ of the yield, was sold at a very low price. This study aimed to optimize the extracting procedure and evaluate the biological activities of Thai organic Riceberry broken rice extracts for anti-aging cosmetology as well as to investigate the stability profile of the extract.

Methods: The extracting procedure, of which deionized water served as a solvent, was varied by spray-drying temperature $\left(150\right.$ and $\left.170^{\circ} \mathrm{C}\right)$ and $\mathrm{pH}$ value (2.0 and 5.5). Antioxidant effects of the obtained extracts were evaluated through 2,2-Diphenyl-1-picrylhydrazyl, 2,2'-azino-bis(3ethylbenzothiazoline-6-sulphonic acid, linoleic acid peroxidation, and ferric reducing antioxidant power assays. Furthermore, the anti-tyrosinase effect was studied through the L-tyrosine pathway. The total phenolic content (TPC) of each extract was evaluated by Folin-ciocalteu's method. The extract, presenting the greatest activity, was then selected for investigating its stability under various storage conditions.

Results: Four Riceberry rice extracts presented noticeable antioxidant and anti-tyrosinase effect. The extract, derived from a spray-drying temperature of $150^{\circ} \mathrm{C}$ and a pH value of 2.0, exhibited the highest effects with the highest TPC (27.08 $\pm 0.67 \mathrm{mg}$ Gallic acid/g extract). This extract also presented a good stability profile. However, this extract should be stored in a high-temperature condition $\left(45^{\circ} \mathrm{C}\right)$ to prevent degradation.

Conclusion: The aqueous extracts of Thai organic Riceberry broken rice could be a promising agent for further developing into anti-aging cosmetology.

Keywords: Thai Riceberry broken rice, Antioxidant, Anti-tyrosinase, Polyphenols, Stability.

(C) 2021 The Authors. Published by Innovare Academic Sciences Pvt Ltd. This is an open access article under the CC BY license (http://creativecommons. org/ licenses/by/4.0/) DOI: http://dx.doi.org/10.22159/ijap.2021.v13s1.Y0027. Journal homepage: https://innovareacademics.in/journals/index.php/ijap

\section{INTRODUCTION}

Aging society is currently considered as one of the most important world megatrends, which highly contributes to the huge market demand for anti-aging products [1]. Anti-aging cosmetics accounted for the largest segment, among other cosmetics. Besides, natural cosmetics are currently regarded as one of the cosmetic trends for the future since the superior perception of the consumers above synthetic cosmetics [2].

Rice (Oryza sativa L.), categorized in the plant family of Poaceae, has been widely consumed since antiquity worldwide [3]. Thailand is regarded as one of the world leaders in rice production. A vast diversity of Thai rice cultivars present their unique physicochemical characteristics [4]. The popularity of Thai organic Riceberry rice, deep purple rice, has continuously gained so far due to the wide variety of nutritional benefits and the extensive increase in the healthy value of Thai society. After the rice polishing procedure, broken rice, which accounted for $20-30 \%$ of the yield, was sold at a very low price [5]. However, this waste product might be a promising antioxidant source, offering an alternative natural substance for anti-aging cosmetics, which can value-add to agricultural waste. Two main anthocyanins, presenting within the rice pericarp, including cyanidin-3-glucoside and peonidin-3-glucoside as well as polyphenols, were principally responsible for its antioxidant vitality $[6,7]$. Settapramote et al. also denoted whether the difference in the agricultural area had a significant effect on polyphenol and anthocyanin contents of Thai Riceberry rice extracts and the rice, grown in Lampang Province, contained the highest number of beneficial chemical constituents [7]. Thus, Thai organic Riceberry broken rice, Lampang cultivar, was studied herein to establish its anti-aging property utilizing evaluation of antioxidant and anti- tyrosinase effects. The extracting procedure, using water as a solvent, was also optimized. Chemical constituents were determined in a term of total phenolic content (TPC). Furthermore, the stability profile of the extract was investigated.

\section{METHODS}

\section{Chemical materials}

Deionized water, used for extraction, was generated by Millipore Milli-Q Advantage (Merck). Reagents, including 2,2-Diphenyl-1-picrylhydrazyl (DPPH), 2,2'-azino-bis(3-ethylbenzothiazoline-6-sulphonic acid) (ABTS), 2,4,6-Tri(2-pyridyl)-2-triazine (TPTZ), and 2,2'-Azobis(2amidinopropane) dihydrochloride (AAPH), were purchased from Merck (Darmstadt, Germany).

\section{Plant materials}

Thai organic Riceberry broken rice was donated from farmers in Lampang Province, Thailand. The sample was harvested at a mature phase in the period of May to June 2019 and discarded from the rice polishing process due to defective, broken shape. The plant material was authenticated by determining total ash and moisture content following the AOAC protocol [8].

\section{Optimization of the plant extraction}

The extracting procedure was carried out by the modified method of Souza et al. [9]. Deionized water served as a solvent herein. The plant mixture, consisting of dry broken rice and water with a ratio of $1: 10$, was heated to reach $70^{\circ} \mathrm{C}$ and continuously stirred for $10 \mathrm{~min}$. The filtrate was then spray-dried with $2 \%$ maltodextrin as a carrier. Factors, possibly influencing extraction, including $\mathrm{pH}$ values (2 and 5.5) and temperatures of spray-drying $\left(150^{\circ} \mathrm{C}\right.$ and $\left.170^{\circ} \mathrm{C}\right)$, was varied relying on the statistical method as 2-level full factorial design (Table 1). The 
Table 1: Experimental matrix, percent yields, and colors of the Thai Riceberry rice extracts

\begin{tabular}{lllll}
\hline Run & \multicolumn{2}{l}{ Extracting condition } & $\begin{array}{l}\text { Percent yield } \\
(\% \mathbf{w} / \mathbf{w})\end{array}$ & Extract color \\
\cline { 2 - 5 } & $\begin{array}{l}\text { pH } \\
\text { value }\end{array}$ & $\begin{array}{l}\text { Spray-drying } \\
\text { temperature }\left({ }^{\circ} \mathbf{C}\right)\end{array}$ & & \\
\hline R1 & 2 & 170 & $8.36 \pm 1.93$ & Deep reddish \\
R2 & 5.5 & 170 & $8.40 \pm 0.89$ & Light purple \\
R3 & 2 & 150 & $7.9 \pm 1.08$ & Deep reddish \\
R4 & 5.5 & 150 & $11.03 \pm 1.32$ & Light purple \\
\hline
\end{tabular}

citric acid $(2 \% \mathrm{w} / \mathrm{w})$ was a $\mathrm{pH}$-adjusting agent. The percent yield and antioxidant activities of each extract were then evaluated and analyzed for determining the correlation.

\section{DPPH assay}

DPPH assay was performed following the modified method of Poomanee et al., [10]. The reaction mixture, containing extract solution and DPPH methanolic solution, was incubated at room temperature in the dark for $30 \mathrm{~min}$. The absorbance was then determined at $517 \mathrm{~nm}$. Free radical scavenging abilities of the extracts were expressed as $50 \%$ inhibitory concentration ( $\mathrm{IC}_{50}$ value)

\section{ABTS assay}

ABTS radical scavenging properties of the extracts were also evaluated by the method of Poomanee et al. with some modification and expressed as Trolox equivalent antioxidant capacity and IC $_{50}$ value [10]. The extract aqueous solutions were mixed with diluted ABTS solution in the ratio of 1:100 and incubated at room temperature for $6 \mathrm{~min}$. The absorbance at $734 \mathrm{~nm}$ was measured.

\section{The inhibitory effect on linoleic acid peroxidation}

Linoleic acid peroxidation assay was carried out for determining the inhibitory effects of the extracts against lipid peroxidation following the method of Poomanee et al. and expressed as $\mathrm{IC}_{50}$ value [10]. To measure the amount of peroxyl radicals, ferric thiocyanate method was performed as the method of Poomanee et al. [11].

\section{Reducing power}

The reducing powers of the extracts were determined using ferric reducing antioxidant power (FRAP) assay and expressed as FRAP value and $\mathrm{EC}_{1}$ value. FRAP reagent $(2 \mathrm{ml})$, consisting of $10 \mathrm{mM}$ TPTZ in $40 \mathrm{mM}$ $\mathrm{HCl}$ solution, $300 \mathrm{mM}$ Acetate buffer, and $20 \mathrm{mM} \mathrm{FeCl}_{3} \bullet 6 \mathrm{H}_{2} \mathrm{O}$, was added with the extract aqueous solution $(1 \mathrm{ml}$ ) and left for $30 \mathrm{~min}$ in the dark. The absorbance of each concentration at $593 \mathrm{~nm}$ was measured.

\section{Anti-tyrosinase activity}

Anti-tyrosinase activities of the extract representing an ability of depigmentation were evaluated through L-tyrosine pathway by the modified method of Poomanee et al. [11]. The effects were reported as $\mathrm{IC}_{50}$ value comparing to those of positive controls, including kojic acid, alpha-arbutin, and l-ascorbic acid. The absorbance of each concentration at $490 \mathrm{~nm}$ was measured.

\section{TPC}

Folin-ciocalteu's method was performed for measuring the TPCs of the extract offering equivalent concentration to that of Gallic acid equivalent. The absorbance at $765 \mathrm{~nm}$ was then measured [10].

\section{Evaluation of the extract's stability profile}

The extract, of which the greatest biological activities presented, was further evaluated for its stability profile under several storage conditions. The extract aqueous solution $(0.5 \%)$ was stored at $4^{\circ} \mathrm{C}$, room temperature with light, as well as without light, $45^{\circ} \mathrm{C}$ for $30 \mathrm{~d}$ and six cycles of heatingcooling (HC) condition ( 1 cycle: $4^{\circ} \mathrm{C}$ for $48 \mathrm{~h}$ and $45^{\circ} \mathrm{C}$ for $48 \mathrm{~h}$ ). After storage, antioxidant and anti-tyrosinase activities were evaluated by ABTS and anti-tyrosinase assays, respectively, and compared to those of the initial. The alterations of color and $\mathrm{pH}$ value were also observed.

\section{Statistical analysis}

All experiments were done in triplicates, and all results were expressed as Mean \pm standard deviation (S.D.). SPSS statistic 17.0 software was performed for statistically analyzing the results of antioxidant, antityrosinase assays, and TPCs through using one-way ANOVA with multiple comparison test of Tukey. In the case of stability testing, a dependent t-test was carried out. p-value less than $0.05(\mathrm{p}<0.05)$ was considered as a statistical significance.

\section{RESULTS AND DISCUSSION}

Thai organic Riceberry broken rice, grown in Lampang Province, was extracted and evaluated for its anti-aging property in this study. Deionized water served as an extracting solvent herein since it is considered as the safest solvent, which potentially extracts polyphenols from plants [12]. The percent yield of each extract (as shown in Table 1) was not significantly different from the others. The difference in colors of the extracts was observed, which was following the $\mathrm{pH}$ value. At $\mathrm{pH}$ 2.0, deep reddish extract powder was obtained, while at $\mathrm{pH} 5.5$, the extracted color was light purple.

Reactiveoxygenspecies(ROS) or freeradicals areubiquitouslyconsidered as one of the important initiators of aging processes [13-15]. By virtue of ROS, oxidative stress, lipid peroxidation, inflammation, and DNAbase alteration are potentiated, which eventually generates several skin aging signs [16]. In this study, we, thus, evaluated free radical scavenging efficacies, reducing power, and inhibitory effects against lipid peroxidation of the extracts for representing its antioxidant and firstly establishing its anti-aging property. Table 2 showed that Riceberry extracts presented free radical scavenging effect and inhibitory effect against lipid peroxidation. Among all extracts, R3, by which the method of the spray-drying temperature of $150^{\circ} \mathrm{C}$ and $\mathrm{pH} 2.0$ extracted, exhibited the greatest antioxidant activities. The results of DPPH and ABTS assays were also corresponding to those of linoleic acid peroxidation assay.

Besides, reducing the power of the extracts, evaluated by FRAP assay, presented similarly to their antioxidant properties. A higher FRAP value indicates the greater capacity to reduce ferric $\left(\mathrm{Fe}^{3+}\right)$ into ferrous $\left(\mathrm{Fe}^{2+}\right)$, whereas a lower $\mathrm{EC}_{1}$ value means a lower concentration that can produce an equivalent reducing effect to that of $1 \mathrm{mM} \mathrm{FeSO}_{4}$. Therefore, $\mathrm{R} 3$ showed the highest reducing power among all extracts, as shown in Fig. 1.

Furthermore, skin hyperpigmentation, causing melasma and pigmentation disorders in the elderly, is partially accelerated in the presence of free radicals since NO ${ }^{*}$ stimulates tyrosinase and tyrosinase-related protein 1 , which are the main components for melanin production [13]. Four Riceberry rice extracts additionally exerted an anti-tyrosinase effect through the L-tyrosine pathway (Fig. 2). At a concentration of $3.125 \mathrm{mg} / \mathrm{ml}, \mathrm{R} 3$ likewise showed the strongest effect. However, the $\mathrm{IC}_{50}$ value of R1, R2, R3, and R4 was $2.42 \pm 0.24,2.30 \pm 0.06,2.13 \pm 0.07$, and $3.33 \pm 0.17 \mathrm{mg} / \mathrm{ml}$, respectively, which were not significantly different between R1, R2, and R3. Our study firstly reported the $\mathrm{IC}_{50}$ value of riceberry rice extract against tyrosinase enzyme. Meanwhile, Teeranachaideekul et al. reported that hydroethanolic extract of riceberry rice exert weak anti-tyrosinase effect [4].

Phenolic compounds play a crucial role in a variety of beneficial effects, especially the antioxidant properties of the natural compounds $[12,17]$. Within pericarp of the purple rice, anthocyanins, and anthocyanidins (aglycone molecules), which were regarded as flavonoid derivatives, considered as one of the polyphenols, were thought to be fundamental constituents [6,7]. In a consequence of hydrogen donation, most of the polyphenols can neutralize free radicals as well as stop the lipid chain peroxidation [12]. Fig. 3 illustrated that R3 contained the highest TPC, which were in correspondence with the results of antioxidant, anti-tyrosinase effects, and reducing power. Moreover, TPCs of Riceberry rice extracts, reported in our study, were approximately 2 -fold higher than the study of Luang-In et al. [5]. It is worth noting 
Table 2: Antioxidant activities of the Thai riceberry broken rice extracts

\begin{tabular}{|c|c|c|c|c|}
\hline \multirow[t]{2}{*}{ Samples } & \multirow{2}{*}{$\begin{array}{l}\text { DPPH assay } \\
\text { IC }_{50} \text { value }(\mathrm{mg} / \mathrm{ml})\end{array}$} & \multicolumn{2}{|l|}{ ABTS assay } & \multirow{2}{*}{$\begin{array}{l}\text { Lipid peroxidation } \\
\mathrm{IC}_{50} \text { value }(\mathrm{mg} / \mathrm{ml})\end{array}$} \\
\hline & & IC $_{50}$ value $(\mu \mathrm{g} / \mathrm{ml})$ & TEAC (mg Trolox/g extract) & \\
\hline $\mathrm{R} 1$ & $0.49 \pm 0.07^{\mathrm{a}}$ & $100.52 \pm 8.10^{\mathrm{b}}$ & $32.29 \pm 0.52^{\mathrm{a}, \mathrm{c}}$ & $0.58 \pm 0.07^{\mathrm{b}, \mathrm{c}}$ \\
\hline R3 & $0.38 \pm 0.05^{\mathrm{a}}$ & $70.06 \pm 5.37^{\mathrm{a}}$ & $33.39 \pm 2.09^{\mathrm{a}}$ & $0.14 \pm 0.01^{\mathrm{a}}$ \\
\hline $\mathrm{R} 4$ & $0.53 \pm 0.01^{\mathrm{a}}$ & $113.76 \pm 8.37^{\mathrm{b}, \mathrm{c}}$ & $28.81 \pm 1.23^{c}$ & $0.50 \pm 0.04^{c}$ \\
\hline Standards & $(\mu \mathrm{g} / \mathrm{ml})$ & $(\mu \mathrm{g} / \mathrm{ml})$ & (mg Trolox/g standard) & $(\mathrm{mg} / \mathrm{ml})$ \\
\hline Trolox & $5.37 \pm 0.69$ & - & - & $0.09 \pm 0.02$ \\
\hline L-ascorbic acid & $29.93 \pm 0.39$ & $2.26 \pm 0.54$ & $838.38 \pm 60.62$ & $0.12 \pm 0.04$ \\
\hline
\end{tabular}

Superscripts ${ }^{(a, b, c)}$ Indicate significant differences between groups using One-way ANOVA with multiple comparison test of Tukey (p<0.05). ABTS: 2,2'-azino-bis(3ethylbenzothiazoline-6-sulphonic acid, TEAC: Trolox equivalent antioxidant capacity

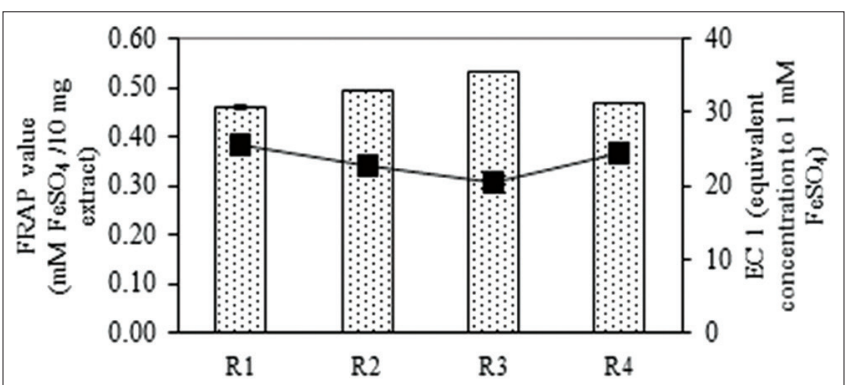

Fig. 1: Reducing power of the Thai Riceberry rice extracts

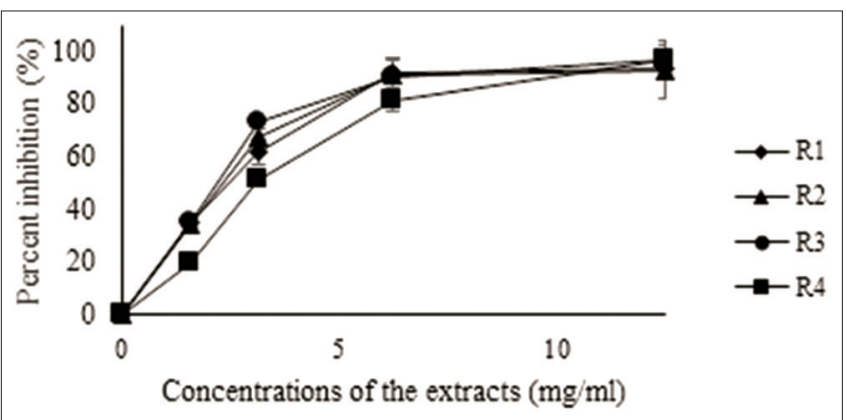

Fig. 2: Anti-tyrosinase effects of the Thai Riceberry rice extracts

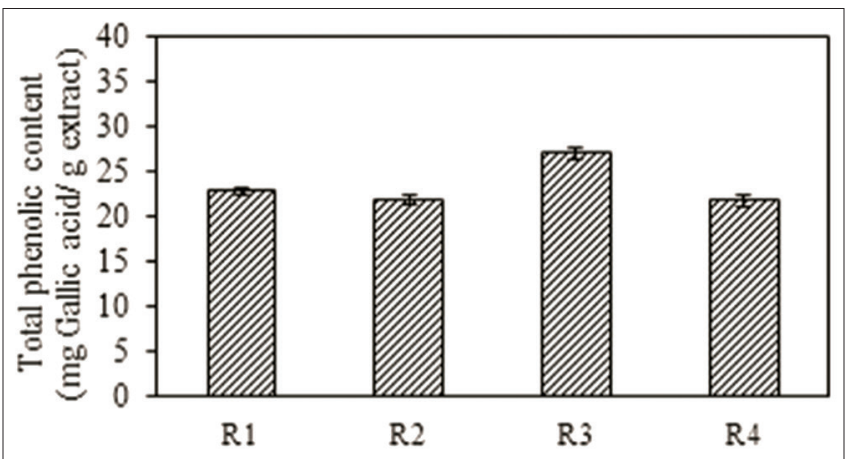

Fig. 3: Total phenolic contents of the Thai Riceberry rice extracts

that the extracting condition had a noticeable impact on the amount of anthocyanins and the biological effects of the extracts. At higher temperature $\left(170^{\circ} \mathrm{C}\right)$, polyphenols tend to be degraded rather than at lower temperatures. Besides, acylation under acidic conditions could enhance the stability of the anthocyanin due to the molecular change from non-acylated anthocyanin into acylated anthocyanin [18]. In our study, citric acid served as an acylating agent due to its non-toxic manner [19]. Interestingly, acylation might additionally have an impact on the biological activities of the anthocyanins. The most adequate

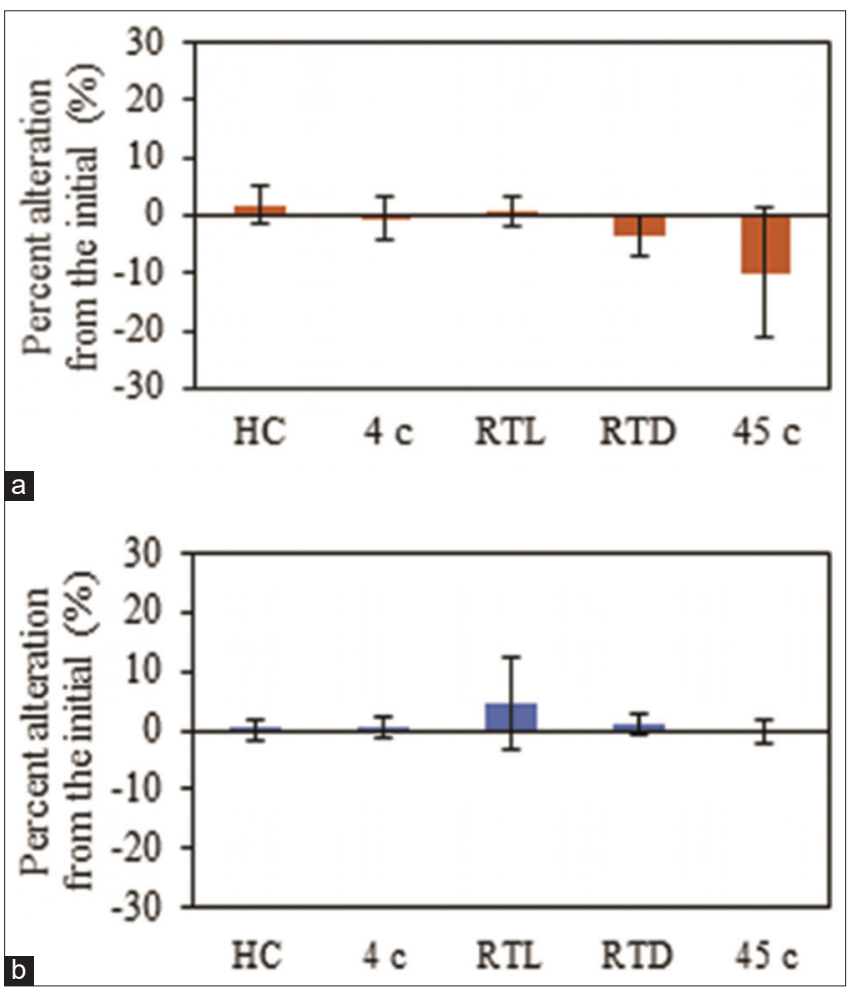

Fig. 4: Percent alteration of (a) 2,2'-azino-bis

(3-ethylbenzothiazoline-6-sulphonic acid radical scavenging effect and (b) anti-tyrosinase effect of the extract (R3) compared to those of the initial

extracting condition was therefore using a spray-drying temperature of $150^{\circ} \mathrm{C}$ and a $\mathrm{pH}$ value of 2.0 . As a consequence, $\mathrm{R} 3$ was chosen for further determining the stability profile.

After storage in various conditions, antioxidant and anti-tyrosinase activities of R3 did not show significantly different from those of the initial (Fig. 4a and b). However, according to (Fig. 4a), the highest reduction in ABTS radical scavenging effect was shown after storage at $45^{\circ} \mathrm{C}$. In addition, after storage at $45^{\circ} \mathrm{C}$ and $\mathrm{HC}$, the obvious fade color was observed. As a result, the extract should be stored in lowtemperature conditions to avoid degradation.

\section{CONCLUSION}

The aqueous extracts of Thai organic broken Riceberry rice, grown in Lampang Province, exhibited notable antioxidant, and anti-tyrosinase properties, correlating to their polyphenol contents. Therefore, this extract could be a promising agent for attenuating skin aging. Nevertheless, to prevent degradation, the extracts should be not stored under high temperatures. 


\section{CONFLICTS OF INTERESTS}

All authors have none to declare.

\section{REFERENCES}

1. Anti-aging Cosmetics Market Analysis, Analysis by Application (Hair Use, Facial Use). By Product Type (Anti-wrinkle, Anti-stretch, Nourishment, Anti-pigmentation, Hair Care, Sun Care Products), by Treatment Type (Cream and Oil, Oral), Forecasts to 2026 Reports. Available from: http://www.reportsanddata.com/report-detail/antiaging-cosmetics-market. [Last accessed on 2019 Aug 15].

2. Mukherjee PK, Maity N, Nema NK, Sarkar BK. Bioactive compounds from natural resources against skin aging. Phytomedicine 2011;19(1):64-73.

3. Ciulu M, Cadiz-Gurrea ML, Segura-Carretero A. Extraction and analysis of phenolic compounds in rice: A review. Molecules 2018;23:1-20.

4. Teeranachaideekul V, Wongrakpanich A, Leanpolchareanchai J, Thirapanmethee K, Sirichaovanichkarn C. Characterization, biological activities and safety evaluation of different varieties of Thai pigmented rice extracts for cosmetic application. Pharm Sci Asia 2018;45:140-53.

5. Luang-In V, Yotchaisarn M, Somboonwatthanakul I, Deeseenthum S. Bioactivities of organic riceberry broken rice and crude riceberry rice oil. Thai J Pharm Sci 2018;42:161-8.

6. Pukdee W, Kumar N, Chaiwut P, Sripisut T. Development of riceberry extract for antioxidant activity. Thailand: MFUIC \& KTCM; 2016. p. 139-46.

7. Settapramote N, Laokuldilok T, Boonyawan D, Utama-ang N. Physiochemical, antioxidant activities and anthocyanin of riceberry rice from different locations in Thailand. Food Appl Biosci J 2018;6:84-94.

8. Association of Analytical Chemists, Arlington. Official Methods of Analysis. $17^{\text {th }}$ ed. Arlington: Association of Analytical Chemists; 2000.
9. Souza V, Thomazini M, Balieiro JC, Favaro-Trindade CS. Effect of spray-drying on the physicochemical properties and color stability of the powdered pigment obtained from vinification byproducts of the Bordo grape (Vitis labrusca). Food Bioprod Process 2013;93:1-12.

10. Poomanee W, Chaiyana W, Mueller M, Viernstein H, Khunkitti W, Leelapornpisid P. In-vitro investigation of anti-acne properties of Mangifera indica $\mathrm{L}$. kernel extract and its mechanism of action against Propionibacterium acnes. Anaerobe 2018;52:64-74.

11. Poomanee W, Chaiyana W, Intasai N, Leelapornpisid P. Biological activities and characterization of the pod extracts from Sompoi (Acacia concinna Linn.) grown in Northern Thailand. Int J Pharm Pharm Sci 2015;7:237-41.

12. Ajila CM, Brar SK, Verma M, Tyagi RD, Godbout S, Valero JR. Extraction and analysis of polyphenols: Recent trend. Crit Rev Biotechnol 2010;31:227-49.

13. Masaki H. Role of antioxidants in the skin: Anti-aging effects. J Dermatol Sci 2010;58:85-90.

14. Papakonstantinou E, Roth M, Karakiulakis G. Hyaluronic acid, a key molecule in skin aging. Dermatoendocrinol 2012;4:253-8.

15. Zhang S, Duan E. Fighting against skin aging: The way from bench to bedside. Cell Transplant 2018;27:729-38.

16. Yaar M, Eller MS, Gilchrest BA. Fifty years of skin aging. J Investig Dermatol Symp Proc 2002;7:51-8.

17. Singh R, Akhtar N, Haqqi TM. Green tea polyphenol epigallocatechingallate: Inflammation and arthritis. Life Sci 2010;86:907-18.

18. Cortez R, Luna-Vital DA, Margulis D, de Mejia EG. Natural pigments: Stabilization methods of anthocyanins for food applications. Compr Rev Food Sci Food Saf 2017;16:180-98.

19. Li T, Wang C, Li T, Ma L, Sun D, Hou J, et al. Surface hydrophobicity and functional properties of citric acid cross-linked whey protein isolate: The impact of $\mathrm{pH}$ and concentration of citric acid. Molecules $2018 ; 23: 2383$. 